\title{
Analysis of Reading Comprehension Skills Reviewed from the Literacy Level of Reading Students in Higher Education
}

\author{
Amril Amir ${ }^{1}$, Afnita ${ }^{2}$ \\ $\left\{\right.$ amril.amir23@yahoo.co.id $\left.{ }^{1}\right\}$ \\ ${ }^{1,2}$ Faculty of Languange and Art, Padang State University, Indonesia
}

\begin{abstract}
Aim to research this for knowing the level of reading comprehension skills in terms of student literacy levels. The population of 300 students. Next, 171 samples of the maha students selected use a stratified random sampling technique. Instrument research is a questionnaire scale Likert and reading skills tests understanding. Data obtained analyzed with variance analysis ( Analysis of Variance / ANOVA). The results showed that the calculated $\mathrm{F}$ value obtained was equal to 5,179 , while Sig. on the degrees of freedom (DK) 1 and alpha $(\alpha) 0.05$ are 0.024 , then according to the hypothesis testing criteria through analysis of variance (ANOVA), Sig. smaller than 0.05 , which means that there are differences in the level of reading comprehension skills of students when viewed from the literacy level. Students who have high reading literacy, the level of reading skills are also high.
\end{abstract}

Keywords : Reading Literacy and Reading Comprehension Skill.

\section{Introduction}

Reading skills occupy important positions and roles in human life. Maha reading becomes a bridge for students who want to have interactive capabilities and integrated. Reading is also regarded as an easy language skill by most maha students, this does not happen on the skills of reading comprehension. The initial problem that arises is the difficulty of understanding reading in its entirety [1][2]. Reading comprehension skills are basic skills for students that they must master to be able to participate in all activities in the process of education and learning [3] [4]. By reading the understanding students can understand the contents of the reading text that has been read. The ability to read is vital in an educated society. Reading is increasingly important in people's increasingly complex lives, because every aspect of life, especially getting information, involves reading.

The tendency to get information through reading has declined from 2003 to $6.05 \%$. Far compared to watching television, the percentage increase is $6.74 \%$. While the 2012 data shows that Indonesians who read to get information only $17.66 \%$ of the total population. Meanwhile, watching television was $91.68 \%$ and listening to the radio was $18.57 \%$. Based on BPS data, the amount of time spent by Indonesian children watching television is 300 minutes per day. This amount is too large compared to children in Australia who are only 150 minutes per day and in America which is only 100 minutes per day. While in Canada 60 minutes per day [5].

Whereas the results of the research program of the International Student Assessment [6] show that reading competence has not shown a significant increase, from 396 in 2012 to 397 points in 2015. The increase raised Indonesia's position 6 ranks up if compared to the second position from the bottom in 2012. The data is different from the increase in the other two 
fields, namely science and mathematics. The biggest increase was seen in science competencies, from 382 points in 2012 to 403 points in 2015. In math, competency increased from 375 points in 2012 to 386 points in 2015. In the same study, PISA also placed the reading position of Indonesian students in 57th place out of the 65 countries studied. PISA said, not even one student in Indonesia won literacy scores in the fifth level, only 0.4 percent of students had level four literacy skills. The rest is below level three, even below level one.

Understanding reading skills are needed by students. This will form a sustainable student mindset. Besides, this skill is very important to absorb information and knowledge from various media. The information obtained can add to the treasury of knowledge and knowledge of various problems, refresh perceptions of things, develop reasoning and eventually expand thinking horizons so that this world does not seem too narrow and is seen not only from one side [7]. Also, Dalman (2013) explained that reading is an activity to apply various skills to process reading texts to understand the contents of the reading. Therefore, reading can be said as an activity to obtain information conveyed by the author. Thus, reading means understanding reading texts both laterally, interpretively, critically, and creatively. According to, reading is a process of interpreting reading in obtaining messages conveyed by the author through his writing. Given that reading is related to the encoding process ( decoding) process ) then the main requirement that must be controlled by the reader must have the ability and understanding of the language and the words that interpret it [8]

To improve reading comprehension skills culture of literacy is needed. Literacy referred to in this study is the frequency of reading. In essence, often doing reading means often practicing, because when someone reads at that time the person is practicing [9]. Frequent practice or reading activities will improve reading skills. This is supported by various research results as revealed, the results of the study show that the ability to read more is determined by the amount of reading time than one's IQ. More people read more about their abilities. Someone will read a lot of their interest in reading is high.

The statement expressed above is in line with Lewis's statement in his book entitled " How to Read Faster and Better " There are six rules for faster comprehension : (1) Read more; (2) Learn to read for main ideas; (3) Challenge your comprehension; (4) Budget your time; (5) Vary your rate; (6) Pace yourself. This opinion confirms the importance of the frequency of reading activities. This frequency will form habits. Next, he analogizes the reader with swimmers. He said to be skilled at swimming, swimmers must do a lot of swimming or practicing activities. To be a skilled reader similar exercises are also needed because then the reader will be able to give a mental reaction quickly to the ideas in the reading [10]

In psychology, power theory is known to be pioneered by Aristotle who said that in principle children have power. Like the power of remembering, fantasy power, and thinking power. These forces, to develop require practice. In the previous section, it has been said that reading means thinking and simultaneously solving problems. The more often someone reads, the more often he does thinking activities and is more experienced in solving problems. Thus, it means that the ability to read it will also increase.

\section{Methods}

This type of research is quantitative descriptive research methods comparative with factorial design models. In addition to descriptive analysis, a comparative study was also conducted which aims to compare data obtained from groups in the population, namely the level of reading comprehension skills in terms of literacy levels (frequency). The population of 300 students. The sample is as much as 171 the maha students. This sample was selected to 
use a stratified random sampling technique. Instrument research this is a questionnaire scale Likert and reading skills tests understanding. Data obtained analyzed with variance analysis ( Analysis of Variance / ANOVA)

\section{Finding and Discussion}

\section{A. Finding}

Data on comprehension reading skills as a whole are obtained from samples (respondents) which number 171 students. Here is the description of data comprehension reading skills as a whole.

Table 1. Description of Reading Comprehension Skills Judging from the level of Literacy

\begin{tabular}{cccc}
\hline Literacy level & $\mathrm{N}$ & Mean & Category \\
\hline High & 41 & 78.2 & High \\
Medium & 77 & 63.6 & Medium \\
Low & 53 & 56.7 & Medium \\
Total & 171 & 66.2 & Medium \\
\hline
\end{tabular}

Based on Table 1, it can be understood that the level of reading comprehension skills in terms of overall literacy level is in the moderate category ( $\mathrm{S}$ ). The highest mean ( reading ) of reading comprehension skills is high literacy. Furthermore, the results of testing the hypothesis of reading comprehension skills variables in terms of literacy levels (high, medium, low) through variance analysis can be seen in Table 2

Table 2. ANOVA Score Data Reading Comprehension Skills Based on Literacy Levels

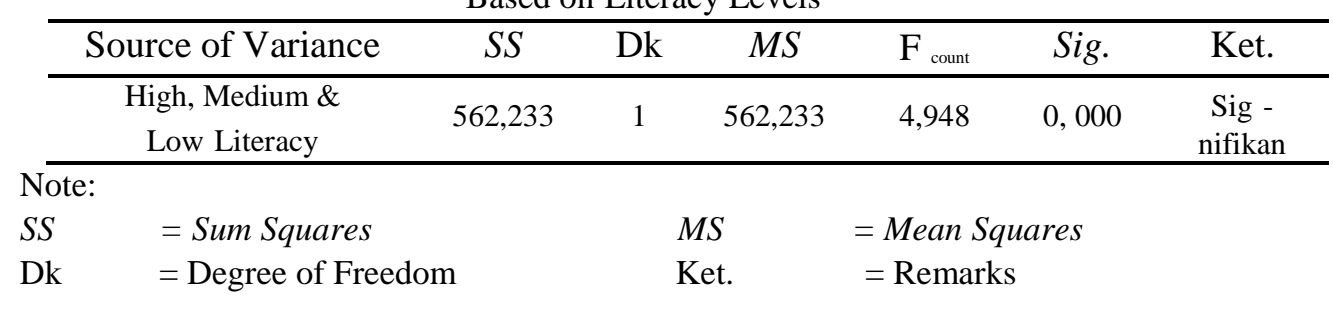

Based on Table 2, it can be understood that the reading literacy variable is high, medium and low, the calculated $\mathrm{F}$ value obtained is equal to 4.948, while the sig. on the degree of freedom (DK) 1 and alpha $(\alpha) 0.05$ are 0,000 , then according to the hypothesis testing criteria through ANOVA, sig. smaller than 0.05 , which means that there are differences in reading skills understanding a significant level between high, medium and low literacy.

\section{B. Discussion}

Life Skills read student understanding is located in a medium category. this indicates that students in understand the text they read it still not optimal. Reading comprehension is the wrong one the most important field for pe and students. This is a process of recognizing symbols written and absorb the message intended in it. Activities this requires various 
abilities. First, the ability to recognize letter written, words, and sentence. Work, the ability to understand the meaning of words and sentences to interpret discourse (reading). Read considered as practices, products, and a process. Weakness in reading comprehensions could too be interpreted as a failure for extract and obtain meaning from text that reads [11]

Reading skills understanding is a very process complicated because involving various factors. Factors that are there are internal (from self reader alone ) and some are of nature external [12]. Besides that, there is various variable or component that affects the performance understanding readings, among them that is knowledge vocabulary, knowledge background back, knowledge system language, metacognitive awareness, knowledge syntax, strategy reading and literacy [13].

In the concept of literacy, reading is interpreted as an effort to understand, use, reflect, and involve themselves in various types of texts to achieve a goal that is to develop one's knowledge and potential and to participate in society ( Liu 2016). Based on this definition, reading is interpreted as an activity of building meaning, using information from reading directly in life, and linking information from text to the experience of the reader. Reading in this sense requires the ability to analyze and synthesize information so that the resulting understanding has a complex meaning structure.

The learning of reading literacy can be interpreted as a series of activities carried out by students to achieve reading comprehension skills [14]. Learning literacy, reading is not solely so that students can read but a process that involves the whole activity of metal and ability to think is most students understand, criticize, and that reproduces a discourse written [15]. In reading literacy learning, students are expected to be able to understand the contents of the reading. To achieve that goal, of course, is most students do not just simply read the material and then answer questions about the content of reading. student should undertake a series of activities to support the achievement of learning objectives [16][17].

The results of the study showed that reading comprehension skills were different in terms of reading literacy levels. This gives a meaning that the higher a person's literacy in reading is predicted to improve reading comprehension skills [2] [18]. As a skill, reading requires exercises like any other skill [19] (Yildiz, 2017). Besides the previous research, revealed that reading continuously or repeatedly can increase understanding for the reader [20]. The more often / often / often students in reading both books, magazines/tabloids and other sources of information, the tendency to read their understanding will be better [21] [16] [22]

\section{Conclusion and Recommendation}

Based on the results of the data and discussion, it can be concluded that the level of reading comprehension is different when viewed from the reading literacy level of students. Students who are literacy level read it high, the reading skill level also tends to be high. This study has implications that achieving a comprehensive understanding in reading requires repeated practice. Readers who often read from various information will be facilitated to absorb and understand the contents of the reading.

\section{References}

[1] S. Van Staden, T. Education, S. Africa, and R. Bosker, "Factors that affect South African Reading Literacy Achievement : evidence from prePIRLS 2011," vol. 34, no. 3, 2014. 
[2] B. Ann and M. Hannon, "The Contributions of Informal Home Literacy Activities to Specific Higher-Level Comprehension Processes," vol. 6, no. 12, pp. 184-194, 2018.

[3] E. Momtaz, "The effectiveness of collaborative reading in tertiary level EFL teaching in Iran Momtaz, Dr. Esmaeil, International College at Robert Gordon University," J. Second Lang. Teach. Res., vol. 4, no. 1, pp. 67-94.

[4] A. Marzban, A., \& Akbarnejad, "The Effect of Cooperative Speed reading on Students' Improving Reading Comprehension of Iranian University," Procedia - Soc. Behav. Sci., vol. 70, pp. 936-942, 2013.

[5] BPS, "Socio-Cultural Indicators," 2012.

[6] PISA, "International PISA Survey," 2016.

[7] J. P. Fraumeni-mcbride, "The Effects of Choice on Reading Engagement and Comprehension for Second- and Third-Grade Students : An Action Research Report," vol. 3, no. 2, 2017.

[8] Y. Liu, "Critical Literacy Practices in EFL Reading Classroom -An Experimental Study towards Chinese University Students," vol. 10, no. 5, pp. 133-138, 2017.

[9] M. I. Tsvetkova, "The Speed Reading is Disrepute: the Advantages of Slow Reading for the Information Equilibrium Contemporary Education ISSN 2304-9650 WARNING ! Article Copying, reproduction, distribution, republication ( in whole or in part ), or otherwise commercial u," Eur. J. Contemp. Educ., vol. 6, no. 3, pp. 593603, 2017.

[10] B. M. Zimmerer, S. T. Skidmore, K. Chuppa-cornell, T. Sindel-arrington, and J. Beilman, "Contextualizing Developmental Reading Through Information Literacy," pp. 2-8, 1908.

[11] J. Harmon and K. Wood, "education sciences The Vocabulary-Comprehension Relationship across the Disciplines : Implications for Instruction," 2018.

[12] E. Brown and J. Rosenthal, "Teaching Strategies to Develop a Family-School Literacy Partnership," vol. 14, no. 1, pp. 31-56, 2018.

[13] A. M. Koksoy, "Examination of 'Art Literacy' Levels of Students Studying in the Education Faculties," vol. 6, no. 5, pp. 101-110, 2018.

[14] Y. G. Kim and R. K. Wagner, "Scientific Studies of Reading Text ( Oral ) Reading Fluency as a Construct in Reading Development: An Investigation of Its Mediating Role for Children From Grades 1 to 4,” no. May, pp. 37-41, 2015.

[15] S. Chudy and D. Vicherková, "Application of Selected Outcomes from PISA and PIAAC Researches to Czech Curriculum and Reading Education," vol. 4, no. 9, pp. 2002-2010, 2016.

[16] L. Zimmerman, "Profiling classroom reading comprehension development practices from the PIRLS 2006 in South Africa," vol. 34, no. 3, 2014.

[17] C. Nel, S. Africa, C. Nel, and C. Commons, "A blueprint for data-based English reading literacy instructional decision-making," pp. 1-9, 2018.

[18] V. S. Damaianti, L. F. Damaianti, and Y. Mulyati, "Cultural Literacy Based Critical Reading Teaching Material with Active Reader Strategy for Junior High School,” vol. 6, no. 4, pp. 312-317, 2017.

[19] I. Liu and H. Ko, "THE RELATIONSHIP AMONG ICT SKILLS , TRADITIONAL READING SKILLS AND ONLINE,” no. Celda, pp. 287-291, 2016.

[20] W.-R. Fluency, T.- Reading, and Y. G. Kim, "Model of Reading Fluency: An Investigation of Predictors of," pp. 1-23, 2015.

[21] M. Kerneža and K. Košir, "Comics as a Literary-Didactic Method and Their Use for Reducing Gender Differences in Reading Literacy at the Primary Level of Education 
Strip kot literarnodidaktična metoda dela in njegova uporaba za zmanjšanje razlik med spoloma v bralni pismenosti na razredni stopnji šolanja," vol. 6, pp. 125-149, 2016.

[22] Y. Beglar, D., Hunt, A., \& Kite, "The effect of Pleasure Reading on a Japanese University efl Learners' Reading Rates. Language learning,” vol. 62, pp. 665-703, 2012. 